\title{
Livros e likes: ponderações sobre o ensino de literatura em tempos de leituras em mídias digitais
}

\author{
Abinalio Ubiratan da Cruz Subrinho (MPED/UNEB)* \\ https://orcid.org/0000-0002-5361-3965 \\ Denise Dias de Carvalho Sousa (PPED/UNEB) ${ }^{* *}$ \\ https://orcid.org/0000-0003-4524-5995
}

\section{Resumo:}

Este artigo problematiza algumas questões referentes ao ensino de literatura na contemporaneidade, principalmente as cisões que são estabelecidas com a não inclusão dos gêneros e textos provenientes da literatura digital nos documentos, programas e práticas escolares. Logo, com tais diálogos, objetivamos propiciar reflexões quanto ao processo de aproximação dos professores, educadores e demais atores que exercem a função de mediadores de leituras literárias com a ficção digital. Para tanto, além das discussões teóricas, recorremos a bases documentais e netnográficas para evidenciar as mutações no campo literário na internet, analisando um dos seus recortes: os booktubers como relevante instrumento na suplementação do ensino e leitura literária, ancorados nas teses e estudos de Cândido (2004), Lima (2014), Rangel (2014), Lévy (1999) dentre outros. Desse modo, constatamos [e reiteramos] a necessidade do debate, uma vez que, para os leitores -internautas esses artefatos já lhes são, em grade parte, familiares; contudo, os currículos, planejamentos e práticas, em alguns casos, ainda cismam em rechaçá.

Palavras-chave: Literatura digital. Ensino de literatura. Booktubers.

\section{Abstract:}

\section{Books and likes: considerations on literature teaching in times of reading through digital midias}

This article problematize questions related to contemporary literature teaching, mainly the established divisions with the non-inclusion of genres and texts deriving from digital literature in school programs and practices. With these dialogues, we aim to reflect on the process of approaching teach-

\footnotetext{
* Mestre em Educação e Diversidade (MPED/UNEB). Professor no Departamento de Ciências Humanas e Tecnologias (DCHT/UNEB). E-mail: ubiratansobrinho80@gmail.com

** Doutora em Linguística e Letras pela PUCRS. Professora permanente do Programa de Pós-graduação em Educação e Diversidade (PPED/UNEB) E-mail: denisecsousa@gmail.com
} 


\begin{abstract}
ers, educators, and other actors who act as mediators of literary readings with digital fiction. For this purpose, in addition to theoretical discussions, we use documentary and netnographic bases to emphasize the variations in the literary field on the internet, analyzing one of its scraps: the booktubers as a relevant instrument in supplementing literary teaching and reading, based on Cândido's (2004), Lima (2014), Rangel (2014), Lévy (1999) theses and studies among others. Therefore, we confirm [and reaffirm] the need for discussion, since, for internet-readers, these tools are already, mostly, familiar; however, the school's curriculum, plans and practices, in some cases, still refuse to accept them.
\end{abstract}

Keywords: Digital literature. Literature teaching. Booktubers.

\title{
Ensino de literatura: mediação em apuros!?
}

Ao dialogar sobre a literatura no contexto escolar Barthes (1989) a coloca num lugar de centralidade ao afirmar que, mesmo se todas as disciplinas fossem suprimidas dos currículos oficiais a literatura deveria permanecer, pois, ela sozinha reúne condições de auxiliar na formação dos sujeitos com conceitos, características e conteúdos oriundos das diversas ciências. Para além dessa questão, o ensino da literatura e da leitura literária em espaços escolares favorecem outras dimensões formativas, as quais transcendem o previsto e normatizado nos programas institucionais, como discute Candido (2004) quando diz que a literatura, antes de qualquer outro potencial, sensibiliza, humaniza. Nessa perspectiva, mediante a tantas benesses que podem ser produzidas pelo contato dos alunos com o literário, tanto nas escolas quanto para além delas (TODOROV, 2010), nos questionamos acerca do premente hiato existente entre a literatura e os leitores nos contextos das salas de aula.

Recorrendo aos dois últimos orientadores oficiais da prática docente e do currículo da escola básica, os Parâmetros Curriculares Nacionais (PCN), em vigor desde 1997, e a Base Nacional Comum Curricular (BNCC), versão final homologada em 2018, podemos constatar a existência de recomendações que norteiam a construção de projetos didáticos, a formação docente e as práticas de ensino no que se relaciona ao trabalho com o texto literário. No caso dos PCN, documento mais antigo, as textualidades se organizam em três volumes: o primeiro destinado a orientações para os formadores da $1 \underline{a}$ a $4^{\underline{a}}$ série do ensino fundamental I, o segundo dispõe de normativas orientadoras aos docentes atuantes entre as $5^{\underline{a}}$ e $8^{\underline{a}}$ séries e, por fim, o último caderno que basila as aprendizagens no Ensino Médio. Todos os documentos são compostos por caracterizações e objetivos gerais da mediação de cada uma das ciências. Nos PCN, o ensino de literatura está atrelado à área de Língua Portuguesa, acionado, de modo geral, no auxílio à aquisição da linguagem e no aprimoramento das práticas de escrita.

Embora ainda muito interligada ao ensino de língua, nas recomendações constantes nos PCN, a mediação literária ganhou novos contornos uma vez que nas propositivas o documento busca ruir com os equívocos históricos que permearam o ensino da literatura durante décadas como, por exemplo, 
as práticas de mediação que tratavam o texto literário como objeto acabado, cujos sentidos já estariam prontos. Por consequência, atividades de leituras que buscavam respostas dos alunos acerca do que o autor quis dizer [preenchimento de fichas de leituras], também interpretações que exploravam um teor moralizante nos textos literários e, sobretudo, ações que se valiam desses escritos como plano de fundo para a análise dos aspectos linguísticos, dentre outras restrições que limitavam os acionamentos e demais efeitos propiciados pela recepção. Na perspectiva de desconstrução, os Parâmetros recomendam:

A questão do ensino da literatura ou da leitura literária envolve, portanto, esse exercício de reconhecimento das singularidades e das propriedades compositivas que matizam um tipo particular de escrita. Com isso, é possível afastar uma série de equívocos que costumam estar presentes na escola em relação aos textos literários, ou seja, tratá-los como expedientes para servir ao ensino das boas maneiras, dos hábitos de higiene, dos deveres do cidadão, dos tópicos gramaticais, das receitas desgastadas do 'prazer do texto', etc. (BRASIL, 1997, p. 29)

É importante destacarmos que, embora os estados, municípios e as instituições escolares tenham construído ou adaptado projetos e diretrizes próprias para o ensino de literatura, durante décadas, foram os PCN que obtiveram a centralidade na condução da prática docente e na construção de recursos didáticos como os livros e os programas de formação de professores. Por essa razão, podemos afirmar que os PCN foram fundamentados na elaboração de propostas cujo ensino de literatura e de leitura literária estivessem mais próximos da fruição estética.

Decorridas duas décadas, em 2017, a BNCC tece diretrizes, legais e obrigatórias, que esteiam os currículos e para além disso estabelecem novas competências e habilidades para o ensino básico em todo território brasileiro. No documento, o ensino de literatura e a formação do leitor literário ganham orientações mais específicas, fluidas que consideram, consubstancialmente, a troca dialética cultural entre leitor e objeto literário, também ampliando as indicações de gêneros a serem trabalhados em sala, explora novos meios de produção, veiculação, leitura (suportes de leitura), com ênfase para os que perpassam os contextos digitais (BRASIL, 2018).

Envolver-se em práticas de leitura literária que possibilitem o desenvolvimento do senso estético para fruição, valorizando a literatura e outras manifestações artísticoculturais como formas de acesso às dimensões lúdicas, de imaginário e encantamento, reconhecendo o potencial transformador e humanizador da experiência com a literatura (BRASIL, 2018, p. 88)

Consideramos pertinente trazer ao diálogo, mesmo que em precisões cirúrgicas, algumas recomendações contidas nos PCN e as instruções legais presentes na BNCC para evidenciar que há algum tempo o ensino de literatura e a formação do leitor literário seguem amparados por normativas e diretrizes gerais oficias. Contudo, mesmo com esse direcionamento, observamos a abismal relação existente entre o que propõem os documentos e programas com os desdobramentos nas salas de aula. Comprovações dessas problemáticas estão evidenciadas em estudos com os de Lázaro e Beauchamp (2008), Rangel (2014) e Subrinho (2019), os quais desvelam a escolarização inadequada da literatura e a consequente apatia dos discentes perante os textos literários apresentados nas salas de aula.

Nesse sentido, buscamos nas pesquisas científicas desenvolvidas por educadores e 
teóricos do campo literário algumas problemáticas que, no contexto escolar, corroborem para perpetuar/ cristalizar a ausência de práticas de ensino que prezam pela fruição da leitura literária.

Um dos primeiros problemas que se instauram é o de ordem estrutural, muitas das instituições púbicas de ensino não contam com ambiências adequadas para que os alunos possam desenvolver as atividades de leitura. Dados do Instituto Nacional de Estudos e Pesquisas Educacionais Anísio Teixeira (Inep), divulgados em 2018, revelam que apenas 55\% das escolas dispõem de bibliotecas ou salas de leituras, situação que se agrava se pensarmos nas condições de funcionamento desses espaços. Em recente investigação, Lima (2017) constata que muitas das bibliotecas escolares não contam com servidor técnico específico ou com propostas internas de fomento à leitura, também de sistema/programa eficiente de preservação e renovação de acervos, sem contar que algumas dessas bibliotecas se tornaram verdadeiros lugares de guarda nos quais os livros não podem ser tocados, pois desorganizamse as estantes/prateleiras e, infelizmente, é cada vez mais recorrente percebermos salas de leituras funcionando como depósitos de objetos em desuso [mimeógrafos, troféus, materiais esportivos desgastados etc].

Para além das questões estruturais, nota-se a escassez de objetos para leitura os livros que integram o acervo das bibliotecas e salas de leituras escolares, maiormente, foram disponibilizados pelo Programa Nacional Biblioteca da Escola (PNBE) do Governo Federal. O programa foi criado em 1997 e fazia a distribuição de livros paradidáticos; de referência, de pesquisa e, sobretudo, de literatura para deleite e formação de professores e alunos. Contudo, a partir do ano de 2014 o programa deixou de ser executa- do, sendo extinto em 2017, e tendo as suas atribuições transferidas, através do decreto Federal N 9099/2017, para o Programa Nacional do Livro Didático (PNLD) que passa a ser nominado Programa Nacional do Livro e Material Didático (PNLD).

Com essa junção, outro agravante se revela para o ensino da literatura e para a leitura literária nas escolas, a ausência de [novos] títulos e em quantidade suficiente para o desenvolvimento de atividades individuais e coletivas. Em decorrência do PNLD, mesmo com o acumulo de funções, priorizar a aquisição dos livros didáticos [o que demanda boa parte do valor do seu orçamento], a montagem e compra de livros literários e outros materiais ficaram comprometidas. As escolas com os poucos recursos financeiros que recebem, diretamente, comumente, oriundos do Plano de Desenvolvimento da Escola (PDE) e do Programa Dinheiro Direto na Escola (PDDE), não conseguem assumir esse espaço lacunar de maior mantenedor das suas estantes.

Recorremos ainda a outro entrave no ensino de literatura, questões sobre os espaços que ela ocupa num dos recursos mais utilizados em sala de aula, os Livros Didáticos (LD), nesse caso em específico, de Língua Portuguesa. Entendemos que as discussões em torno do LD são demasiadamente complexas, por inúmeros motivos, alguns desses podem ser verificados em Coscarelli e Cafieiro (2013), De Pietri (2007) e Sousa $(2018,2019)$. Contudo, ao tecer essas analises nos limitamos a questões referentes às abordagens literárias. Nesses materiais, a literatura aparece de modo tímido. Nas coleções destinadas ao ensino fundamental, por exemplo, há uma construção centrada na apresentação dos gêneros literários iniciando com as fábulas, contos clássicos até se chegar aos romances. 
Quanto aos livros do Ensino Médio, de modo predominante, a tão criticada linha historiográfica das escolas e movimentos literários, como constata Sousa (2019, p.7-8):

A abordagem dos conteúdos, temas e textos literários, bem como o viés teóricometodológico que sustenta o desenvolvimento das atividades propostas nos três volumes [Português Contemporâneo: Diálogo, Reflexão e Uso (2016)], com vistas à formação do leitor, limita-se a um ensino de literatura pautado na historiografia literária - características dos estilos de época a partir do estudo de textos de autores brasileiros canônicos. As atividades propostas exploram a compreensão e a interpretação textual dos textos; porém, dá-se pouca importância às atividades que englobam processos de intertextualidade e interdiscursividade, bem como à apresentação de textos de autoria feminina.

Em ambos os ciclos formativos são perceptíveis: a apresentação de obras literárias a partir de fragmentos [mesmo com os gêneros curtos], atividades que ainda cultivam a análise dos textos a partir da observação do bom estilo, indicações desvinculadas das leituras prévias dos alunos o que os distanciam do prazer proporcionado na leitura do literário.

Também aproximamos do diálogo outro recurso indispensável [e de fundamental importância] ao ensino de literatura e para formação de alunos-leitores literários; o professor. É a partir da atuação docente que as distâncias entre o aluno e Carolina Maria de Jesus, Guimarães Rosa, Stephenie Meyer e tantos outros e outras podem ser encurtadas ou drasticamente ampliadas. É evidente que não pretendemos responsabilizar unicamente o professor o que se configuraria enorme equívoco. Porém, é indubitável a sua relevância nesse processo, no estímulo e no jogo de sedução.
Ainda que muitos dos cursos de formação de professores de Artes, Língua Portuguesa e Literatura se filiem a teorias e interpretações oriundas da Sociologia da Leitura, da Estética da Recepção, do Letramento Literário e demais estudos que conferiram mais autonomia ao leitor, ainda há cadeiras e práticas que concebem a literatura num tom bacharelesco, agravando a situação de carência quanto às metodologias de dinamização da leitura. Nesse sentido, observamos em inúmeros relatos de alunos e professores a transposição dessas práticas - das salas dos cursos de graduação e pós-graduação para as salas de aula na escola básica -. Por essa razão, conforme observam Lajolo e Zilberman (2009) e Martins (2006), os professores necessitam revisitar as suas ações didáticas, atualizá-las a fim de se aproximarem das leituras prévias dos alunos, auxiliando-os (re)construção de sentidos, pois, "Ter prazer na leitura, sobretudo na leitura de alguns textos, exige iniciação". (MARTINS et al, 2013, p. 124) e embora existam outros espaços e agentes mediadores de leitura literária, ainda são a escola e os professores os principais agenciadores do letramento literário.

Mediante a esse cenário de tantas problemáticas, arrastadas há algum tempo, inferimos que não é fácil para o professor estabelecer dinâmicas que favoreçam o consumo da literatura como um direito (CANDIDO, 2004), um fenômeno/bem cultural (MARTINS, 2006) ou ainda como um lugar de travessias (ECO, 1994) principalmente na contemporaneidade, quando os discentes se aproximam de outros fazeres literários, consumindo gêneros, autores, obras e adaptações que circulam nos multimeios, principalmente na internet espaço ainda não alcançado pelas escolas, um lugar impensável. 


\section{Com quantos likes se faz a literatura contemporânea?}

Está distante de ser nova a face camaleônica da literatura. No decorrer dos séculos, por diversas razões, a arte da palavra se adaptou a diferentes suportes e mídias. Podemos constatar essa característica desde as primeiras manifestações literárias presente nos jornais impressos, perpassando pelas rádios - com as radionovelas - ou servindo de referência para construção de obras cinematográficas, também para as adaptações de novelas e séries televisivas até chegar aos desdobramentos contemporâneos, quando se torna matéria-prima no desenvolvimento de games, redes sociais, como o Skoob, de aplicativos e plataformas online que acomodam conteúdos literários, a exemplo da Wattpad, e que ampliam, exponencialmente, as possibilidades de circulação dos textos, em suas mais variadas composições, assim como o número de leitores de literatura.

A construção e adequação das obras literárias em/para outros suportes além dos livros despertou e ainda desperta em parte da crítica e dos leitores um certo desconforto, desconfiança quanto a preservação do seu potencial estético, também quanto a possibilidade da realização de leituras que assegurem a fruição. Nesse sentido, ao passo que um novo meio de produção e de hospedagem é alçado escritores, leitores e demais sujeitos, mais afeitos às formas tradicionais de escrita e de veiculação literária, alerdavam de modo apocalíptico o fim do livro, de uma das práticas culturais de leitura e da própria literatura. No entanto, o que observamos é a repercussão do efeito contrário a literatura ganha capilaridade ao ser lançada nas infovias ascendendo em novos números de gêneros e de textos adaptados também favorecendo a emergência de novos gestos de leitura e de perfis leitores, como pode ser observado nas pesquisas de Chartier (1998) e Santaella (2011, 2014).

A literatura está presente na internet desde quando a rede resguardava a exclusiva função de arquivo. Nesse período, numa estratégia de preservar e/ou de difundir obras, alguns poucos sites e internautas passaram a escanear ou moldar formatos diversos para disponibilizarem textos oriundos dos suportes impressos para os meios online, também passam a compor esse ciberuniverso resumos e resenhas de obras literárias. Como é perceptível, nesse primeiro momento não há uma marca muito significativa quanto a produção literária na web o que se registra é a criação de novos ambientes para leitura e de novos modos de ler, como expresso no pensamento de Coscarelli e Cafiero: "Agora, os tempos mudaram, o avanço tecnológico proporciona computadores, tablets, celulares e outros recursos que têm reinventado a leitura e mudado as formas de o leitor agir sobre o texto". (COSCARELLI; CAFIERO, 2013, p. 10)

Com a cultura digital alcançando cada vez mais usuários, a internet, por meio das suas atualizações, passou a acumular outras funções, além da de depósito, repositório para armazenamento e consulta de informações e arquivos de modo geral. Dentre as mais exponenciais está o favorecimento da comunicação, de modo síncrono e assíncrono entre os internautas - é nesse período em que se criam as comunidades, páginas e sites de relacionamento -, um desses ambientes, massivamente explorado, foram os blogs. Esses sítios, páginas/diário possibilitavam que os responsáveis pelos perfis postassem e interagissem com os mais diversos conteúdos. 
Sobre essa tessitura, os estudos de Lima (2014) evidenciam que a blogosfera se tornou, também, um espaço ocupado pela literatura, servindo de palco para construção, veiculação e recepção literária ambiência “[...] em que autores e leitores assumem papéis ainda mais dinâmicos, diante da interatividade dos meios eletrônicos". (MARTINS, 2006, p. 97). Acerca da relação entre os blogs e a literatura Schollhammer discute:

As novas tecnologias oferecem caminhos inéditos para esses esforços, de maneira particular, com os blogs, que facilitam a divulgação dos textos, driblando os mecanismos do mercado tradicional do livro, bem como o escrutínio e o processo seletivo das editoras. (SCHOLLHAMMER, 2011, p. 13 grifos nossos)

Schollhammer (2011) constrói apontamentos a partir da observação do que ocorre com os blogs. Suplementamos o pensamento do autor acrescentando e exemplificando com o que também ocorre com outros sítios e redes como, por exemplo, o Facebook, o Instagram, o Twitter e o YouTube. É evidente que as grandes editoras ainda continuam exercendo forte influência sobre a seleção e difusão dos textos literários, contudo, é importante sublinhar que um ruído vem se instaurando nessa relação. É ascendente a quantidade de escritores que se valem dos ambientes virtuais e dos recursos que esses espaços disponibilizam para construir e disseminar suas obras para que os leitores possam apreciá-las, também recorrendo às redes para abrir canais de diálogo e interatividade com o público a exemplo do que pode ser observado nos perfis dos autores Fabrício Carpinejar, Marcelino Freire, Thalita Rebouças e Sérgio Vaz.

Percebemos também que, além dos ficcionistas já legitimados pela crítica e pelas escolas em suas recomendações de leituras obrigatórias, as comunidades, fóruns e páginas conferem espaço para que outros escritores e estéticas textuais sejam produzidas e lidas independente do escrutínio das editoras, como evidencia Schollhammer (2011). Assim como se constata a dinâmica inversa: autores e textos até então "anônimos" nos meios físicos impressos, pela quantidade de acesso (compartilhamentos e curtidas), participação (comentários), nos escritos, chamam a atenção dos grandes grupos editorias como ocorreu com os autores Anna Todd, em After, e com Geovani Martins, em O Sol na Cabeça. Independente da questão referente à aderência das editoras, tornouse mais acessível ler e produzir literatura com a internet, o que é altamente positivo, haja vista que o consumo do livro impresso, por justificativas variadas, ainda é distante de muitos leitores e ademais a profusão de autores, temáticas, discussões, indicações favorece o encontro dos ledores literários, principalmente os iniciantes, como textos que estão próximos das suas expectativas leitoras e por consequência lhe tocam mais, desse modo contribuindo para o seu letramento literário.

Outro aspecto relevante a ser considerado sobre a concepção de leitura nos ambientes online é a intermidialidade. A intermídia é uma noção que denota a relação que acontece entre as diferentes mídias e linguagens artísticas, assim como entre arte e mídias. Nos contextos digitais essa convergência ocasionou a criação de um fazer literário peculiar, o qual só pode ser construído e lido nesses espaços por meio de suportes que acolham o universo digital. Estão presentes nessas práticas a elaboração de: novos gêneros, adaptações e releituras em formatos de GIFS, vídeo-poemas, narrativas em games dentre outras que demandam da interpretação dos sons, dos movimentos pro- 
duzidos pelos códigos escritos e imagéticos, assim como, com os labirintos do hiperlinks para auxiliar na construção de sentidos.

Os leitores-navegadores encontram na rede uma série de instrumentos que lhes possibilitam experienciar a fruição estética do texto literário: o agrupamento em comunidades que viabilizam o compartilhamento e o debate sobre a literatura podem também se avizinhar dos textos de margem e massa, assim como participar mais ativamente da cultura de fã, seguindo seus autores prediletos, conhecendo novos ficcionistas, produzindo fanfics, fanarts, mashups literários. Diversos estudos se somam para evidenciar que o contato com os meios digitais construiu um novo perfil leitor, navegador, desbravador, interativo, ubíquo, multissemiótico, hiperconectado ledores que, segundo Wolf (2019), são desafiados a desenvolverem outros processos cognitivos e de concentração para experienciar a leitura profunda online, principalmente com os textos literários. Dado esse contexto, nos questionamos como os agenciadores, formadores de leitores literários, podem acolher esses alunos em suas diversas leituras auxiliando -os na construção de significados? Como os professores podem enriquecer a formação leitora desses discentes que a cada dia, e com mais frequência, destinam horas a navegação na $w e b$ ?

\section{Tá na rede: booktubers e os ensino de literatura}

Primeiro, queremos demarcar que o desencadeamento de uma disputa por espaço entre os suportes de leitura já se apresenta como uma questão superada. 0 virtual não quer se sobrepor ao impresso e o contrário também não acontece, ambos são esteios diferentes de escrita e leitura frutos da tec- nologia cultural de um determinado período. Logo, o que está em debate é a formação de leitores literários e a suplementação das práticas de leitura com auxílio dos recursos digitais, situações de aprendizagem que as escolas e os professores, principalmente os de língua portuguesa, não podem mais postergar.

Há alguns anos os jovens vêm buscando referências de leituras literárias alternativas das que lhes são apresentadas nas escolas: bruxos, feiticeiras, vampiros best-sellers, narradores de aventuras e sagas teen que compõem a estante dos alunos. Nas últimas décadas, esses sujeitos estão desbravando novos ambientes, roteiros, trajetos, autores e personagens na internet, o tempero que parece faltar nas aulas de literatura é o que dá sabor às criações e reinvenções literárias existente nas redes.

Nesse sentido, o ensino de literatura deve se aproximar do digital por inúmeras razões, aqui podemos elencar algumas centrais tais como: a consonância com as recomendações oficiais contidas nos PCN, na BNCC e nas filosofias educacionais mais contemporâneas no que tange ao ensino contextualizado, e no contexto vivencial do aluno, que é cada vez mais híbrido; entre os espaços físicos e os digitais. Também pela razão desses novos textos apresentarem peculiaridades que demandam estratégias de leitura específicas para o meio digital e nesse sentido: "É preciso que o leitor considere a situação de comunicação em que o texto se insere". (COSCARELLI; CAFIERO, 2013, p. 20).

Logo, com essa cena, o professor necessita ressignificar a sua prática, tornando-se também um leitor e pesquisador dessa literatura, construindo estratégias a partir do uso das textualidades dispostas nos ambientes virtuais para assim alcançar os alunos, pois: "Para que a leitura e a literatura pos- 
sam receber um tratamento didático compatível com a sua dimensão cultural, também a concepção de ensino deve assumir outro perfil". (RANGEL, 2014, p. 45). Nessa perspectiva, um relevante instrumento que pode favorecer esse contato inicial é o YouTube, mais especificamente os Booktubers.

No YouTube a literatura aparece de diversos modos e assume diferentes formas: nas entrevistas concedidas por escritores, leitores, especialistas, em documentários, curtas-metragens, vídeopoemas, adaptações e releituras de obras, também no ascendente fenômeno que se tornaram os booktubers. Esses leitores-comentaristas constroem canais nas plataformas de vídeos e ecoam: a) críticas literárias embasadas em teóricos, estudiosos; b) apresentam resumos e resenhas de romances; c) recitam poemas; d) dramatizam, expressam, de forma descontraída e dinâmica (detalhe que colabora no jogo de sedução aos internautas) opiniões acerca de várias obras; do cânone à literatura de margens.

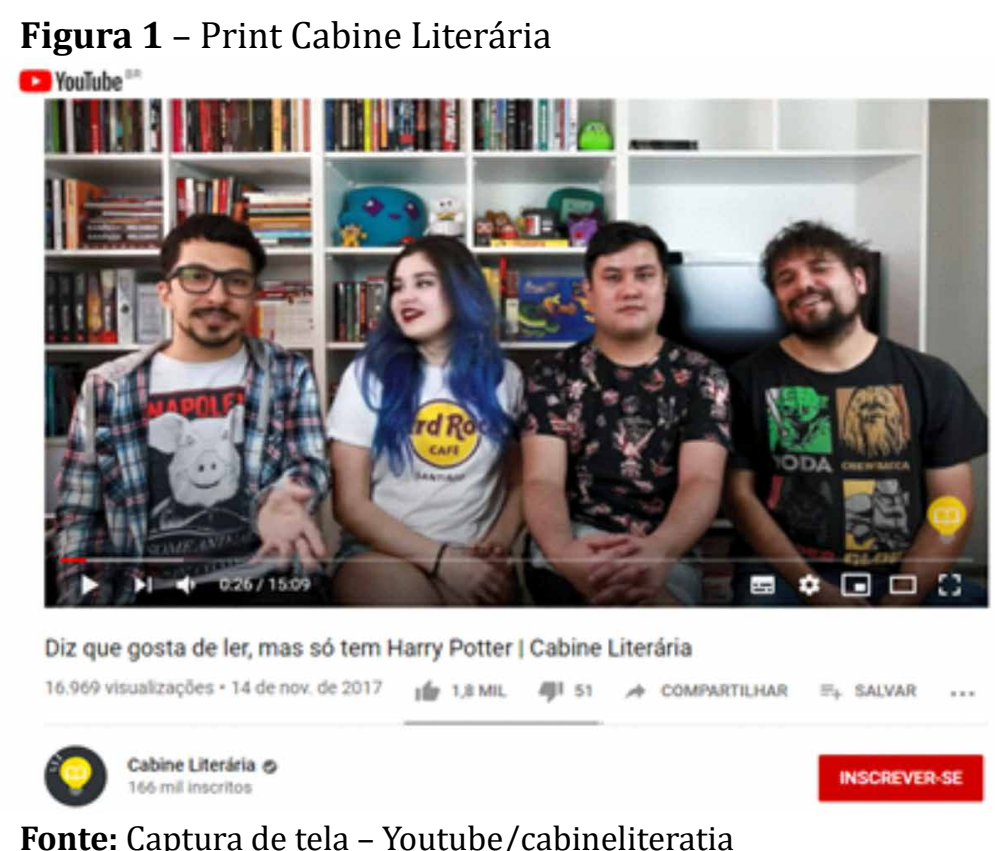

$\mathrm{Na}$ imagem acima, cristalizada a partir do registro de um print, estão os booktubers responsáveis pelo canal Cabine Literária. No vídeo em questão os jovens debatem acerca de uma mensagem publicada num perfil no Twitter, "Diz que gosta de ler, mas só tem Harry Potter". Evidentemente, infere-se que o autor de tal construção buscou inferiorizar a prática de leitura dos bestsellers, da literatura de massa. No diálogo, o coletivo discute questões como acesso à leitura literária, inferiorização de alguns eixos da produção. A maior facilidade que se tem na contemporaneidade para acesso [a leitura] e publicação dos livros, níveis de leitura e o lugar do Estado na formação dos leitores.

Assim, recorremos a esse recorte para ilustrar o quão contributivo para formação pode ser as redes sociais e os muitos conteúdos disponibilizados/construídos nelas. Nesses vloggers além de apresentar, de modo panorâmico ou mais minuciosamente, obras literárias, os canais-livros no YouTube fomentam discussões que, por diversas razões, nem sempre são desencadeadas em salas ou, ainda, podem ajudar na suplementação dos conhecimentos que são construídos em aula. Logo, o professor pode acionar os booktubers de diversos modos 
para os auxiliarem no ensino de literatura e na leitura literária por meio de práticas.

É possível citar alguns exemplos. Apresentar aos alunos a plataforma YouTube em sua função de sala de leitura, uma vez que para muitos desses sujeitos a dimensão leitora é desconhecida - comumente os internautas consomem os shows e clipes dos seus artistas e bandas favoritas. Com a mídia apresentada é necessário possibilitar que os discentes entrem em contato com múltiplos canais em suas centenas de resenhas, para que a partir do toque com essas narrativas eles possam selecionar quais obras desejam realizar a leitura.

A interação com os vídeos-indicações somada ao processo de autonomia desenvolvido pelos alunos a partir da escolha das obras que desejam ler contribui, significativamente, para adoção de didática adequada no fomento à leitura, mais propensa aos alunos alcançarem a fruição, pois, como discute Rangel (2014), uma das principais barreiras que se erguem entre os alunos e a literatura na escola é a ausência de identificação com as obras que lhes são impostas, principalmente para aqueles discentes que estão no início da incursão. Logo, uma maneira de ruir com esse muro é exatamente possibilitar, de modo orientado, que eles possam montar as suas estantes de leitura, uma vez que, como observa Kleiman (2014), para o professor consiste em uma "enorme dificuldade de achar um texto didático que comungue com vinte, trinta ou quarenta subjetividades" (KLEIMAN, 2014, p. 7) principalmente quando nos remetemos à complexa heterogeneidade presente nas salas de aula das escolas públicas.

É evidente que quando damos ênfase à concepção de leitura de outros textos, além dos que já estão cristalizados nos programas, de modo algum queremos rechaçar ou dimi- nuir a importância da leitura das obras clássicas, buscamos sinalizar, sim, que a imposição ou a limitação do trabalho com essas narrativas acabam tendenciado uma divisão entre literatura x subliteratura, também não dando conta da multiculturalidade acessada/vivenciada pelos alunos, nesse sentido "É imprescindível que o professor reavalie suas leituras, a fim de também levar a produção de autores contemporâneos para sala de aula, até com o objetivo de questionar o cânon literário". (MARTINS, 2006, p. 90) e com os booktubers alunos e professores poderão conhecer inúmeras dessas diversas produções.

Os professores podem aproveitar o dinamismo do YouTube e das postagens nos canais, para que os alunos interajam com os vídeos e com outros leitores por meio do recurso comentário, alongando os sentidos do conteúdo publicado, registrando suas inferências, participando dos debates também no ambiente virtual. Para além desse momento formativo, uma rica e necessária estratégia que pode servir de fio motivacional para esses alunos leitores-navegadores é recorrer à convergência das mídias (JENKINS, 2006) e à cultura da participação (SHIRKY, 2011) para que possam se tornar booktobers, semeadores de leitura.

Após conhecerem e experienciarem a dinâmica de funcionamento dos canais o professor e os alunos, em ação colaborativa, podem criar uma página de conteúdo literário. Os vídeos serão fruto das experiências de leitura dos educandos nos quais eles irão apresentar obras literárias, protagonizar debates, incentivando a prática de leitura de outros sujeitos. No amparo a atividades desse cunho, nas Competências Gerais, a BNCC determina:

4. Utilizar diferentes linguagens - verbal (oral ou visual-motora, como Libras, e escrita), corporal, visual, sonora e digital -, bem 
como conhecimentos das linguagens artística, matemática e científica, para se expressar e partilhar informações, experiências, ideias e sentimentos em diferentes contextos e produzir sentidos que levem ao entendimento mútuo. (BRASIL, 2018, grifos nosso)

O grande estúdio de elaboração desses artefatos será a sala de aula. É importante que antes da produção dos vídeos ocorram debates nas aulas, em momentos como tertúlias literárias ou rodas de leitura, para que o coletivo possa auxiliar com sugestões no processo de montagem dos vídeos, também para que o aluno-booktuber se sinta mais seguro na elaboração de suas reflexões. Cabe aos atores selecionarem qual a periodicidade de postagem dos vídeos, em quais espaços as imagens serão produzidas, se os alunos apresentarão conteúdos de modo individual ou em grupos dentre outras questões. Caso a escola não disponha de recursos tecnológicos como filmadora os celulares do professor ou dos alunos podem ser utilizados.

É importante que na condição de coordenador da atividade, o professor assegure a autonomia e estimule o potencial criativo dos alunos, fugindo de roteiros definido, nos quais a centralidade esteja em informar característica das personagens, quadro da época, dados biográficos e demais caracterizações, que já são velhas características das aulas de literatura. Antes, é necessário dar vazão à fruição estética experienciada pelos alunos. O coletivo pode propor outras ações e inserir outros sujeitos, quem sabe converter num projeto de leitura da escola ou da comunidade.

\section{Algumas considerações}

Ao findarmos a escrita desse artefato, percebemos que ainda há muito mais para ser es- tudado e dito, em razão da própria mutação que acomete a literatura desde sempre, movimento esse percebido com mais premência das últimas décadas do século XX com a emergência dos novos suportes de escrita e de leitura. Assim como pela velocidade e intensidade da cultura digital, características abordadas por nós algumas vezes no texto, fatores que corroboram para que as produções literárias nas plataformas digitais agreguem novas características, possibilidades de veiculação e de estratégias para alcançar o leitor. Porém, não podemos deixar de evidenciar algumas constatações.

A primeira questão a ser aventada é a premente necessidade de ressignificar o ensino de literatura nas escolas, principalmente no que tange à mediação e às abordagens que são adotadas para leitura e análise dos textos. Logo, pela relação de fascínio, de atratividade e pela ampla aderência que os alunos, sábios digitais, nutrem aos recursos tecnológicos online, e nesse espaço realizam diversas leituras. Assim, colocamos as novas produções literárias, autores emergentes na rede e ambientes interativos para leitura como vetores na promoção dessas mudanças, na contemporaneidade. É preciso que a e-literatura, aparentemente, mais familiar aos alunos esteja a serviço do encadeamento da autonomia leitora e sirva, também, de "isca" para outras leituras e outros modos de ler.

É importante demarcar, também, que quando dialogamos sobre a importância da leitura contextualizada não queremos dizer que os sujeitos em formação leitora inicial; no estágio suplementação de suas práticas ou ainda na ampliação dos níveis do letramento, devam ser, exclusivamente, expostos aos objetos, temáticas, viagens, cujas narrativas lhe sejam familiares, contextuais, porém, esse é um importante movimento para 
atrair os discentes para o universo da leitura desconstruindo as recorrentes e, sabidas por nós, erróneas, equivocadas falas que adjetivam a literatura como chata, monótona...

Quando aproximamos esse diálogo aos canais-livros não é nossa pretensão sugerir que, necessariamente, os professores se tornem Youtubers ou que os booktubers possam substitui-los em sua função de mediadores, de entusiastas do leitor literário, muito pelo contrário. Pois, com a facilidade para publicação e a ausência de filtros há alguns canais que apresentam, como podemos dizer... leituras não autorizadas por determinados textos, questões que podem confundir ou até mesmo afastar ainda mais os sujeitos da literatura, logo, reside aí mais uma relevante função do professor: selecionar, debater, expor e contrapor as informações e percepções contidas nos vídeos. Desse modo, ponderamos que, embora mudem os suportes, os gêneros ou os meios de produção, o professor segue sendo um importante ator no processo de mediação, assim como, torna-se irrefutável a necessidade de uma profunda reflexão e aproximação da literatura digital aos momentos de ensino e de deleite nos contextos escolares.

\section{Referências}

BARTHES, Roland. Aula. Trad. Leyla PerroneMoisés. 14.ed. São Paulo: Cultrix, 1989.

BRASIL. Secretaria de Educação Fundamental. Parâmetros Curriculares Nacionais: língua portuguesa. Brasília, 1997.

BRASIL. Ministério da Educação. Base Nacional Comum Curricular. Educação é a base. Brasília: MEC, 2017.

CANDIDO, Antônio. 0 direito à literatura. In: CANDIDO, Antônio. Vários escritos. 4. ed. São Paulo/Rio de Janeiro: Duas Cidades/Ouro sobre Azul, 2004, p. 169-191.

CHARTIER, Roger. A aventura do livro: do lei- tor ao navegador. Trad. Reginaldo Carmello Corrêa de Moraes. São Paulo: Editora UNESP, 1998.

COSCARELLI, Carla Viana.; CAFIERO, Delaine. Ler e ensinar ler. In: COSCARELLI, Carla Viana. (Org.). Leituras sobre a leitura: passos e espaços na sala de aula. Belo Horizonte: Vereda, 2013

DE PIETRI, Emerson. Práticas de leitura e elementos para atuação docente. Rio de Janeiro:Lucerna, 2007.

ECO, Umberto. Seis passeios pelo bosque da ficção. São Paulo: Companhia das Letras, 1994.

JENKINS, Henry. Cultura da convergência. Trad. Susana Alexandria. São Paulo: Aleph, 2006.

LÁZARO. André; BEAUCHAMP, Janete. A escola e a formação de professores. In: AMORIM, Galeno (org.). Retratos da leitura no Brasil. São Paulo: Imprensa Oficial: Instituto Pró-Livro, 2008.

LÉVY, Pierre. Cibercultura. Trad. Carlos Irineu da Costa. São Paulo: Ed.34, 1999.

LIMA, Elizabeth Gonzaga de. Geração blogueira: a literatura na web. In: CORDEIRO, Verbena Maria Rocha; LIMA, Elizabeth Gonzaga de (org.). Modos de ler: oralidades, escritas e mídias. Curitiba: Arte e Letra, 2014.

LIMA, Rita de Cássia Brêda Mascarenhas. Bibliotecas escolares: realidades, práticas e desafios para formar leitores. 2017. $285 \mathrm{f}$. Tese (Programa de Pós-graduação em Educação) Universidade Federal da Bahia, Salvador, 2017.

MARTINS, Ivanda. A literatura no ensino médio: quais os desafios do professor? In: BUNZEN, Clécio; MENDONÇA, Márcia (org.). Português no ensino médio e formação do professor. São Paulo: Parábola, 2006.

MARTINS, Aracy Alves et al. Espaços da literatura. In: COSCARELLI, Carla Viana. (org.). Leituras sobre a leitura: passos e espaços na sala de aula. Belo Horizonte: Vereda, 2013.

RANGEL, Egnon de Oliveira. Leitura, literatura e docência. In: CORDEIRO, Verbena Maria Rocha; LIMA, Elizabeth Gonzaga de (org.). Modos de ler: oralidades, escritas e mídias. Curitiba: Arte e Letra, 2014.

SANTAELLA, Lucia. A aprendizagem ubíqua 
substitui a educação formal? Revista de Computação e Tecnologia da PUC-SP - Departamento de Computação/FCET/PUC-SP, São Paulo, v.3, n.1, p.17-22, 2011.

SANTAELLA, Lucia. O leitor ubíquo e suas consequências para a educação. In: Patricia Lupuion Torres (org.). Complexidade: redes de conexões na produção do conhecimento. 1ed. Curitiba: Kairós Edições, 2014, v. 1, p. 27-44.

SCHOLLHAMMER, Karl Erick. Ficção brasileira contemporânea. 2. ed. Rio de Janeiro: Civilização Brasileira, 2011.

SHIRKY, Clay. A cultura da participação: criatividade e generosidade no mundo conectado. Rio de Janeiro. Zahar, 2011.

SOUSA, Denise Dias de Carvalho. Abordagem das literaturas africanas no livro didático de língua portuguesa do ensino médio. In: Anais do XIX Encontro Nacional de Didática e Práticas de Ensino, v. 1, n. 40, p. 2-14, Salvador: UFBA, 2018.
SOUSA, Denise Dias de Carvalho. 0 ensino de literatura sob a perspectiva do livro didático de língua portuguesa do ensino médio. Pensares em Revista, São Gonçalo-RJ, n. 16, p. 70-80, 2019.

SUBRINHO, Abinalio Ubiratan da Cruz. Em touches e em cliques: a formação leitora por intermédio das redes sociais da internet. 2019. 160 f. Dissertação (Mestrado Profissional em Educação e Diversidade) - Universidade do Estado da Bahia, Jacobina, 2019.

TODOROV, Tzvetan. A literatura em perigo. Trad. Caio Meira. 3. ed. Rio de Janeiro: DIFEL, 2010.

WOLF, Maryanne. 0 cérebro no mundo digital: os desafios da leitura na nossa era. Trad. Rodolfo Ilari e Mayuri Ilari. São Paulo: Contexto, 2019.

Recebido em: 15/05/2020 Aceito em: 18/06/2020 